\title{
Los problemas de saneamiento en las grandes poblaciones
}

De unos años a esta parte la Ciencia del Urbanismo va tomando carta de naturaleza en nuestro país, y poco a poco se va infiltrando en el ánimo de gobernantes y gobernados, llevando al mismo un conocimiento cada día más completo de los problemas de las urbes y un criterio de acometer estos problemas con un sentido orgánico y de conjunto.

Pero también es forzoso reconocer que, hasta ahora, los técnicos urbanistas, es decir, aquellos encargados del desarrollo de las teorías urbanas y de plasmar en proyectos, obras y servicios, las modernas concepciones para transformar, reformar o extender nuestras ciudades, han polarizado sus esfuerzos e inteligencia hacia lo que podríamos llamar planeamiento superficial, para orientar los trazados y las ordenaciones visibles a las normas y necesidades de los tiempos actuales, que son de plena evolución.

Esto va siendo logrado con más o menos acierto, ya que en este como en todos los problemas de la técnica, el aspecto personal domina e imprime su sello, aunque el trabajo haya de sujetarse a determinadas normas científicas; y. en nuestras ciudades españolas se va dejando sentir la influencia de los estudios de las Comisiones Provinciales de Ordenación Urbana, y en el caso de las grandes aglomeraciones, de los Organismos especiales que, como el del Gran Bilbao, han sido creados y están funcionando.

El tratamiento de los trazados viarios, la implantación de las adecuadas zonificaciones, la reglamentación más cuidadosa intro- 
ducida en las Ordenanzas, van consiguiendo, quizá lentamente, un tratamiento del vuelo, de los edificios, en una palabra, de lo que se ve sobre el suelo, que armoniza más con las ideas artísticas $y$ estéticas y con las exigencias técnico-sanitarias que la vida moderna impone, y que hoy día son de obligada consideración en toda ciudad que quiera merecer el nombre de tal.

En cambio, desgraciadamente, no se ha hecho más que comenzar a abordar el problema que la existencia de nuevos servicios urbanos de higiene, confort y trabajo ha creado, y que requiere la organización adecuada, y con un margen grande de revisión de servicios, generalmente alojados en el subsuelo, y que no por quedar invisibles son menos fundamentales para la vida urbana.

Ello se traduce en un freno mucho mayor de lo que la gente cree para el desarrollo superficial urbano y la vida de relación de las distintas zonas de la ciudad. Hasta le extremo de que no vacilamos en afirmar que de no acometerse su estudio e implantación, también con carácter integral, con un programa a largo plazo, nunca inferior a cincuenta años, y con unas normas de ordenación y de previsión que permitan las ampliaciones sucesivas que la ciudad vaya demandando, no solamente frenará la expansión de las urbes, sino que se complicará y encarecerá más de día en día, haciendo cada vez más difícil su resolución.

Si me permitís haré uso de una interpretación, un poco "sui generis" es cierto, de una parábola bíblica: la de Marta y María.

Desde un punto de vista urbanista yo encuentro plenamente justificada la queja que, según el Evangelio, elevó Marta al Señor, alegando que su hermana María dedicaba todo su tiempo al cuidado externo, a la veneración, y a lo que podríamos llamar "estétican en el tratamiento que ambas hermanas daban a Nuestro Señor, al honrarles éste con su visita, pues sin la labor callada, oscura y eficaz de Marta, organizando la casa, atendiendo a las necesidades de la comida y al cuidado de sus huéspedes, es muy posible que la labor más brillante de María o no pudiese realizarse, o habria de cesar pronto para atender a las necesidades inmediatas.

Así, pues, difícil será crear una población bella, agradable y sana por mucho que se cuide la Estética, los Trazados y las Edi- 
ficaciones, si no está cimentada sobre la firme base de los servicios fundamentales, que son: Abastecimientos de agua, Alcantarillado o Saneamiento, Limpieza pública, Vialidad, Alumbrado y Tráfico y Transportes, y aun podemos añadir modernamente el de Piscinas.

Para analizar las características fundamentales de las obras que requieren estos principales servicios técnicos urbanos y su explotación, los agruparemos en tres conceptos :

a) Servicios del subsuelo.-Aguas, alcantarillados y canalizaciones diversas.

b) Servicio del suelo.-Pavimentación y limpieza.

c) Servicios del vuelo.-Tráfico y Transportes, Piscinas y Alumbrado.

Claro está que muchas veces, quizá más de las debidas, el orden de establecimiento de estos servicios se altera por razones de orden personal o de política social, que no tienen nada que ver con el Urbanismo; y no son raros los casos en que se comienza por pavimentar, después se instala el agua, a veces sin el alcantarillado (o viceversa), cuando en realidad estos dos servicios deben ser considerados como hermanos siameses, y finalmente se levanta el pavimento cuantas veces se precisa para alojar los cables y las tuberías de alumbrado, gas, teléfonos, etc.

Abastecimiento de aguas.

El abastecimiento ide aguas debe estar concebido con un amplio criterio moderno, tanto en cuanto a cantidad como en cuanto a calidad.

Respecto de la primera, hay que olvidarse de aquellas dotaciones de 50 litros por habitante y día, señaladas por la vigente Ley de Aguas, y partir de la base, al menos, de la de 200 litros por habitante y día, señalada en el Estatuto Municipal de 1924 y legislación posterior.

Pero esto no basta en las grandes aglomeraciones, pues la realidad viene demostrando que en estas concentraciones humanas de tipo progresivo el consumo aumenta rápidamente y no puede aceptarse menos de 300 litros por habitante y día. 
Con estos caudales unitarios, aplicados a la cifra de población, contada por centenas de millares, se llega a caudales de abastecimiento que no es posible ya pensar en encontrar en los clásicos manantiales, ni en alguno que reúna per sé las adecuadas condiciones de potabilidad y pureza bacteriológica.

Por ello habrá que hacer frente a la corrección de los cuatro grandes grupos de impurezas que contendrán las aguas posibles de abastecimiento, que son :

$10^{\circ}$ Impurezas en suspensión.

2. Impurezas en disolución.

3. Impurezas coloidales.

4. Impurezas bacteriológicas.

La eliminación de las primeras, o sea de la turbiedad, ya hace indispensables las instalaciones de decantación, a base de permanencia en tanques durante veinticuatro horas, o de circulación por los mismos con velocidad reducidísima de $0,005 \mathrm{~m} / \mathrm{seg}$.

Como, generalmente, las materias en suspensión irán acompañadas de otras en disolución y coloidales, será preciso activar la sedimentación mediante reactivos que coagulan dichas impurezas, y que precipitándolas en forma de corpúsculos pequeños, eliminan las mismas, especialmente la arcilla coloidal, y con ello una gran parte de las bacterias.

La técnica moderna va siempre más allá de una decantación con coagulación, y la acompaña casi siempre de una filtración, bien sea en filtros lentos o rápidos.

En estos momentos la tendencia casi universal es la aplicación de filtros rápidos, de forma a exigir que el agua filtrada a su través tenga menos de 100 bacterias por centímetro cúbico, aunque este criterio no sea absolutamente eficaz contra infecciones, pues es posible que entre esas 100 bacterias se halle alguna patógena.

La elección de filtros rápidos, abiertos o cerrados, depende ya de razones técnicas locales, que no es posible reducir a normas fijas.

En nuestro país, hasta ahora, van teniendo más aceptación los abiertos, y así nosotros estamos terminando en Jaén una instalación capaz para tratar 100 litros por segundo, y recientemente 
hemos informado la construída por Granada y actualmente en servicio, que llega a los 400 litros por segundo.

Otro de los inconvenientes que suelen tener las aguas españolas es su dureza, y por ello es preciso ir pensando en corregirla mediante saturadores con aparato regulador, cámara de reacción y filtro rápido.

Ahora bien; lo más importante de asegurar en un agua es ia pureza bacteriológica, y por ello hoy se hace imprescindible en las grandes poblaciones el contar con estaciones de cloración, bien sea por cloro o hipoclorito (con o sin amoníaco) o por procedimientos de ozonización, que en nuestro país por diversas razones no se han desarrollado apenas.

Un aspecto interesantísimo de los abastecimientos han de ser los depósitos de regulación, que han de emplazarse estratégicamente para servir, con las menores pérdidas de carga posibles, las necesidades de las redes, y que deben tener una capacidad equivalente, como mínimo a un día de consumo.

Si las poblaciones son llanas es preciso ir pensando en la multiplicación de torres de agua, emplazadas próximas a los centros locales de consumo, con arquitectura externa que favorezca las pers. pectivas urbanas de la zona de emplazamiento y con capacidad precisa para varias horas.

En casi todas las grandes poblaciones que han crecido desmesuradamente, se está dando el fenómeno de insuficiencia en las redes de distribución.

Este fenómeno por otra parte es muy lógico, puesto que cuando se establecieron las actuales, ni la densidad urbana de las zonas servidas era la actual, ni el caudal de que se disponía era suficiente (aunque sí lo fuera para las necesidades de entonces), ni la técnica había avanzado lo suficiente para dictar normas para ei cálculo de estas redes.

Por ello, casi ninguna está prevista para los caudales máximos instantáneos, que no son los medios de abastecimiento, sino de dos a dos veces y media el normal; según la clase de vida y el clima de la ciudad.

Los inconvenientes de que las redes sean insuficientes no son 
sólo los de la falta de presión y el dejar desabastecidas muchas viviendas en los momentos de consumo alto, lo que obliga a montar instalaciones de elevación y depósitos caseros que alteran por completo las condiciones sanitarias del agua, aparte de los gastos que produce a la propiedad.

Hay otro peligro mayor, que es el que se presenta también en los casos de cortes, cual es la existencia de una depresión en las tuberías que facilita las contaminaciones de fuera a dentro.

Si a esto se une que en casi todas nuestras poblaciones no se ha tenido la precaución de asegurar que las tuberías de agua estén por encima de colectores y cajas de registros, sumideros y otros lugares de posible contaminación por aguas residuales, se comprenderá la razón de la aparición de brotes epidémicos en sectores concretos urbanos, que tantos trastornos suelen producir.

Claro está que la máxima garantía higiénica para esto, la constituye el alojamiento de los tubos en galerías de servicios, en las que están fuera de toda contaminación y en las que las fugas se acusan inmediatamente, para ser corregidas en el acto.

Con esta solución no hay peligro en caso de vaciado temporal, y se evitan las pérdidas producidas por las fugas, que llegan en casi todas las redes a un porcentaje del 20 al 25 por 100 .

\section{Alcantarillado.}

No creo sea preciso destacar los peligros de un subsuelo contaminado, y por tanto es axiomática la afirmación de que se impone el alejamiento de las aguas residuales con completo aislamiento del terreno y con la rapidez adecuada para evitar putrefacciones, con su secuela de producción de olores y gases.

El decidir si las redes de alcantarillas han de ser únicas o de sistema separativo, es cuestión que en cada gran población decidirán razones técnicas, topográficas y económicas. Sin embargo como norma general parece que lo más lógico es la red unitaria.

Pero si hay que prever elevaciones del afluente y no es posible instalar aliviaderos en algunos puntos de los grandes colectores, que permitan verter a cursos de agua próximos los grandes 
caudales de lluvia, habrá que pensar en el establecimiento de redes dobles.

También en los alcantarillados es muy frecuente en las grandes poblaciones encontrarse con secciones insuficientes, construídas esporádicamente, con urgencia, como suelen pedir muchos Ayun. tamientos, y casi siempre con presupuesto tope, que es otro de los males que suele padecer la técnica municipal, y sin pensar en su servicio futuro.

Claro está que mientras la población no haya tenido un plan concreto de ensanche y extensión, ha resultado sumamente difícil el prever las redes de alcantarillas y colectores, con vistas a su utilización presente y futura.

Pero este mal afortunadamente va acabando y hoy son ya mayoría, si no totalidad, las grandes ciudades españolas con su plan de ordenación y extensión aprobado.

Por ello es imprescindible que las Corporaciones de estas grandes ciudades acometan el estudio del plan general de saneamiento con carácter definitivo, y una vez aprobado, vayan realizándose los colectores principales de cada uno de los sectores, para que en todo momento el saneamiento, en unión del abastecimiento de aguas, vaya por delante de las urbanizaciones.

Este problema, que se presenta ahora en Madrid con caracteres más acuciantes por el enorme aumento de superficie y núcleos urbanizables por las anexiones, obliga a redactar planes de saneamiento integral de zonas periféricas, si se quiere evitar la anarquía que hasta ahora ha venido presidiendo en esta importante rama del saneamiento urbano.

Complemento obligadísimo de esta medida es la depuración y el aprovechamiento posterior de las aguas residuales.

No sólo porque nuestra legislación municipal obliga a efectuar esta depuración, sino porque hoy día no puede admitirse que las grandes poblaciones se desentiendan del problema sanitario agudo que crean con sus aguas de vertido sin depuración, es forzoso completar la red de saneamiento con la construcción de dichas estaciones depuradoras, unas o múltiples, según las circunstancias locales y topográficas. Pero es que además, hay otra considera- 
ción de orden económico que no suele apreciarse, y es la de que resulta un poco de salvajismo, podríamos decir, el que se gasten sumas ingentes en la aportación de caudales para los usos públicos y privados, y que estos caudales sean después, no solamente desaprovechados totalmente, sino causa de perturbación sanitaria de los cursos de agua y núcleos habitados próximos a la capital.

$\mathrm{Y}$ estos problemas se presentan análogamente en las poblaciones costeras, pues la solución de vertido al mar, pura y simplemente, aparte de los inconvenientes que en algún caso puede presentar desde el punto de vista económico, tiene los de orden sanitario de la polución de playas y costas.

Las conclusiones a que se ha llegado en este aspecto en los pasados Congresos de la Asociación General de Higienistas y Técnicos Municipales, de carácter internacional, en Niza en 1949, y en Biarritz en el año actual, permiten afirmar la necesidad de estudiar racionalmente esta evacuación al mar, si se aspira a cuidar las condiciones sanitarias de las poblaciones de la costa.

En este aspecto justo es reconocer que, salvo Madrid, que construye una perfecta instalación depuradora que debía estar ya en servicio hace varios años si las dificultades de adquisiciones de materiales básicos: hierro, cemento y maquinaria, unidas a las trabas administrativas que en estos tiempos de anormalidad impiden contratar en forma a imprimir la mayor rapidez a las obras urgentes, no lo hubiesen impedido. Poco o nada se ha hecho en nuestras grandes ciudades, pues incluso Barcelona que convocó, hace más de quince años, un concurso de anteproyectos en el fué premiado uno mío, nada ha realizado hasta la fecha.

De todos modos es casi seguro que en el año próximo comience a funcionar parcialmente la de Madrid, y se pueda acometer sin tardanza la puesta en riego de $550 \mathrm{Ha}$. en el plan mínimo y de 2.000 como máximo, con la entrega del agua debidamente depurada para su aprovechamiento en el canal del Jarama, unos kilómetros aguas abajo de Vaciamaidrid.

En estas depuraciones no hay que perder de vista el coeficiente de purificación a alcanzar, que depende en gran parte del destino posterior de las aguas y de la dilución que puedan éstas experimentar en cauces próximos. 
Es decir, que no conviene dejarse alucinar por sistemas complicados y muy perfectos técnicamente, sino acudir a soluciones suficientemente prácticas y de una explotación lo más sencilla posible, pues de todos es sabido las dificultades que posteriormente presentan los presupuestos municipales para recargarse con gastos de conservación y explotación.

Concretamente, si la población tiene una gran vía de agua próxima, habrá que estudiar una depuración estrictamente precisa para asegurar la depuración suficiente de gérmenes por autodepuración al hacer el vertido, si es que no hay aprovechamiento agrícola anterior, o si es que éste por tener el carácter de los cultivos herbáceos o forestales, no completa la depuración.

Es decir, que hay que estudiar en qué etapas de la depuración residual hay que detenerse de las cuatro que podemos considerar; a saber :

1. ${ }^{a}$ Simples rejillas y areneros cuando el vertido puede hacerse en grandes cursos de agua, bien aireado y batido, o en costas debidamente estudiadas en su régimen de corrientes.

2. Lo anterior más una decantación en tanques, cuando la dilución en cursos de agua es suficiente al eliminar las sustancias gruesas y finas en suspensión.

3. ${ }^{\text {a }}$ Completada con una desintegración de las sustancias en suspensión y disolución mediante tanques Imhoff o de otro tipo análogo, cuando hay que extremar la clarificación y disminuir la demanda bioquímica de oxígeno del efluente para reducirla a la capacidad del curso de agua receptor.

4. ${ }^{\text {s }}$ Terminación con una depuración biológica posterior para alcanzar un alto porcentaje de depuración. Esta puede ser mediante campos de riego, filtros percoladores, filtros bacterianos de ventilación forzada, fangos activos o tratamientos químicos, y dentro de éstos, especialmente la cloración.

Insistimos en que según sea el problema urbano a resolver $y$ la estabilidad del efluente que se trate de alcanzar, así habrá que limitarse a una, dos, tres o a las cuatro etapas antes citadas.

No entro en el detalle de las características que han de reunir tanto tuberías y colectores, como los elementos auxiliares de un 
alcantarillado: registros, cámaras de descarga automática, absorbedores, sifones si existen aliviaderos, etc., por tratarse de asunto exclusivamente técnico y extraño al alcance de esta conferencia.

Solamente diré que el emplazamiento y constitución de estos elementos es muy interesante para un normal funcionamiento de la red general de alcantarillado.

\section{Canalizaciones diversas.}

Aparte de las canalizaciones de agua y alcantarillado, las grandes poblaciones han de dar cabida en su subsuelo a las siguientes:

a) Cables eléctricos enterrados de alta y baja tensión.

b) Cables telefónicos y telegráficos.

c) Gas.

d) Canalizaciones especiales, tales como correo neumático, calefacción a distancia y distribución de aire comprimido, aunque de estas últimas todavía no tengamos ejemplos en España.

Si los primeros se colocasen con sujeción a las modernas normas técnicas de profundidad, distancia entre sí, protección contra cargas exteriores, aislamiento y derivaciones bien establecidas, $\mathrm{v}$ si las calles de nuestras grandes ciudades tuvieran amplitud para permitir la aplicación de estas normas, nada habría que objetar desde el punto de vista urbanístico y sanitario, salvo el que el peligro de producción de corrientes vagabundas no dejaría de existir, con el consiguiente perjuicio para las tuberías de fundición.

Pero como ello requiere mucho espacio, que no tienen nuestras viejas calles, mucho cuidado en la instalación de nuevos cables, que no es humanamente posible exigir a las Empresas, y mucho espíritu ciudadano, la consecuencia es que el número de cables va creciendo, su colocación absoluta y relativa se hace caótica, las averías se suceden ininterrumpidamente, y las famosas calas (azotes de los pavimentos y de la circulación urbana), se multiplican en progresión geométrica, complicándose con las debidas a las tuberías de agua y gas.

Estos inconvenientes de orden urbano producidos por las calas, tienen un aspecto sanitario muy importante, ya que la remoción del suelo favorece: el desarrollo de los gérmenes que en el 
mismo se cultivan y pueden dar lugar a contaminaciones de las aguas freáticas, e incluso de las tuberías de distribución, especialmente en los momentos (como los actuales) en que existen subpresiones y puestas en vacío de dichas tuberías.

Ello explica la 'aparición en algunos momentos en algunas grandes poblaciones de epidemias tíficas en sectores determinados, a pesar de resultar perfectos los análisis del agua en las salidas de los depósitos.

Las tuberías de gas, si están colocadas bajo las aceras y tienen la suficiente estabilidad sin perturbar por las calas, no suelen tener tantos inconvenientes urbanistas, pero si las calas aparecen, los macizados se hacen siempre mal y se producen arrastres de tierras por fugas de agua o hundimientos de alcantarillas, automáticamente aparecen las fugas de gas, que dan lugar a operaciones enojosas de comprobación y localización, y al peligro de explosiones aisladas, como suelen presentarse en nuestras ciudades algunas veces; y ello aparte de las grandes pérdidas de flúido, que cuestan mucho dinero a las Empresas o a los Municipios que explotan las instalaciones de gas.

Todo ello hace que en estas grandes poblaciones se vaya imponiendo cada vez más una solución mixta, a saber : Colocación de las canalizaciones con sujeción a normas de separación y deposición relativa y debajo de las aceras, doblando los servicios en aquellas calles en que por su anchura o su menor importancia en cuanto al número de servicios se refiere, lo permita, y ejecución de galerías de servicios de dimensiones suficientes para alojar todas las canalizaciones (salvo el gas por el peligro de fugas, difíciles de combatir), y de efectuar en ellas todas las maniobras y reparaciones necesarias.

En este aspecto podemos hablar con la autoridad que da el resultado práctico de los once kilómetros de galerías que hemos construído en Madrid en estos años, con secciones de tres tipos distintos, para acoplarse a las diferentes características de calles y servicios del subsuelo, y en las que hemos tenido la satisfacción de que cuantas personas, especialmente técnicos nacionales y muchos extranjeros, han visitado dichas galerías, han hecho elogios 
extraordinarios, y, lo que es mejor, han manifestado su propósito de trabajar por su implantación en los distintos países.

Claro que para ello es preciso que las galerías respondan a las siguientes condiciones :

a) Facilidad de recorrido, instalación de servicios y su renovación e independencia relativa a las canalizaciones entre sí.

b) Inaccesibilidad de personal, salvo por determinados puntos en los que ha de existir un cuarto de guardia para el control $\mathrm{y}$ acompañamiento de los obreros que hayan de efectuar reparaciones.

c) Entradas de materiales intervenidos y bien emplazados para la distribución de los mismos.

d) Ventilación adecuada por dispositivos naturales si la topografía lo permite, o artificiales si se precisa. Iluminación conveniente para la vigilancia y conservación, y desagües bien emplazados para los casos de roturas accidentales en las tuberías.

e) Acometidas visitables también entre la galería y las fin. cas servidas, pero sin posibilidad de acceso al interior de estas galería. $\mathrm{Y}$

f) Conservación adecuada e inspección asidua y permanente.

La mayor limitación que estas galerías de servicios tienen, es su coste, pero aún así, si se hace el cálculo económico de los derechos de calas, del coste de las mismas para las Empresas y de los trastornos al tránsito público, así como de los derechos municipales por ocupación del subsuelo, se verá que cuando el número de estas canalizaciones es algo importante, la solución es ventajosa.

\section{Pavimentación.}

Los pavimentos a emplear han de responder a unas condiciones que no son arbitrarias como, al parecer, creen muchos concejales cuando se lanzan a proponer tipos determinados para las calles. $Y$ entre ellas, no son las menos importantes las sanitarias.

La impermeabilidad de ciertos pavimentos que no sólo facilite su limpieza y baldeo en beneficio de la atmósfera urbana, sino que evitando penetraciones en el subsuelo o reflujo de ésti sobre el exterior acabe con la perniciosa acción del agua infiltrada y 
con muchas de las acciones telúricas que destrozan pronto con firmes.

La resbaladicidad, que ha de guardar relación con las pendientes de las calles y con el tráfico que éstas han de soportar, para evitar los accidentes de la circulación a vehículos y peatones que, aunque no sean causas patológicas, sí lo son de morbilidad y mortalidad.

La sonoridad, tan poco estimada en nuestros días y que sin embargo, si hemos de hacer caso de las observaciones de los médicos, es una de las causas de producción y mantenimiento de muchas enfermedades nerviosas.

El estudio de las características de las zonas residenciales, debe aconsejar en muchos casos unos tipos de pavimentos de la menor sonoridad, y que transmitan peor las vibraciones circulatorias a las estructuras de los edificios.

La visibilidad que tanta relación guarda con los accidentes de la circulación y que puede llevar a aconsejar prescindir en muchas calles céntricas de los firmes oscuros (tipos asfálticos o basálticos), y a proteger adecuadamente los bordillos haciéndoles resaltar con pinturas discretas, pero no abusivamente empleadas.

El reblandecimiento por el calor que impide en muchos casos, especialmente en climas cálidos el empleo de firmes bituminosos, cuya capa superficial cede, se ondula y se deshace bajo la acción combinada del calor y del tráfico.

Razones sanitarias son las que aconsejan proscribir de las calles en general, los macadams corrientes, productores constantes de polvos y barros, almacenadores de microbios, procedentes de toda clase de residuos urbanos, y difíciles de conservar en adecuado estado, aún combinados con riegos alquitranados o asfáltico superficiales.

No obstante, como firmes provisionales en calles de nueva apertura, aún no consolidadas, o en nuevas urbanizaciones de tipo ciudad jardín, o barriadas modestas, pueden emplearse.

\section{Limpieza pública.}

Con la autoridad que me dan mis veinte años de lucha con este servicio en el Ayuntamiento de Madrid y en algunos otros de Es- 
paña con mis informes y asesoramiento, puedo decir que este Servicio, llamado de Sanidad Nueva, no se ha sentido en su justo va. lor en nuestra patria.

Hablar de los peligros sanitarios, de los polvos viarios y de las basuras caseras y públicas, sería pueril.

Solamente diré que los tres aspectos fundamentales son:

1. ${ }^{\circ}$ Barrido y riego.

2. Recogida de basuras urbanas.

3..$^{\circ}$ Tratamiento de las mismas.

El barrido a mano o a máquina debe siempre ir precedido de un ligero riego previo que evite la producción de polvo. Y en ello radica su dificultad cuando es manual, pues es difícil organizar debidamente las brigadas de riego y.barrido. Solamente si se hace con autobarrederas con dispositivos de riego previo, se logrará este extremo. Aunque estas máquinas no son baratas y aunque generalmente son movidas por gasolina (grave dificultad en momentos especiales) hay que atender a su utilización. $\mathrm{Y}$ en las grandes capitales, conviene tender hacia las grandes barrederas-regadoras, que ejecutan indistintamente uno u otro servicio con 1.500 y 3.000 , y hasta 5.000 litros.

Si los pavimentos son buenos y están bien conservados, pueden emplearse las autobarrederas-cargadoras, que riegan, barren y recogen la basura, llenando automáticamente sus grandes depósitos de $2 \mathrm{~m}^{3}$ que solamente vacían en determinados sitios, para su cargue en los camiones de recogida. Las modernas regadoras suelen llevar dispositivos de lavado con chorros inclinados o bocas para injertar mangueras, con el fin de proceder de vez èn cuando a dichos lavados.

Por cierto que el público se extraña de que se lave el pavimento cuando llueve o recién llovido, y lo censura como un despilfarro de agua y mala organización municipal. Lo cierto es que es cuando, por la blandura de la capa adherida al pavimento y de la temperatura, es más eficaz el lavado.

Complemento de la limpieza viaria que debe hacerse una vez al día como mínimo, es el repaso permanente en ciertos lugares urbanos y cuyo fin es mantener libre el suelo de lo que ensucian 
los ciudadanos. Debe practicarse con cepillo, cogedor y carritos de poca capacidad y muy manejables.

Los dos elementos principales de una buena limpieza urbana son: Buenos pavimentos y cultura urbana que no ensucie la calle y la respete.

El empleo de basuras frescas o verdes está prohibido, lo cual quiere decir que, hasta ahora, casi todas las ciudades no lo cumplen.

Las basuras han de tratarse 0 :

Por vertido controlado debidamente organizado con capas alternantes de tierra que permiten una adecuada fermentación natural y su empleo en agricultura al cabo de algunos años.

Por relleno de barrancadas, socavones o terrenos pantanosos, adoptando las debidas precauciones para la no contaminación de las capas de agua.

Por triturción en máquinas especiales que al producir una oxidación de la materia orgánica determinan una depuración que permite su almacenamiento y empleo posterior sin mucho temor a las moscas.

Por fermentación zimotérmica en cámaras cerradas (generalmente sistema Beccari) en las que la fermentación natural durante 33 días, ayudada por la circulación de aire y adición de caldos o purines de fermentaciones anteriores, determina una elevación de temperatura hasta $60-65^{\circ}$ y una suficiente depuración para ser empleadas como abono.

Por incineración en hornos especiales autocomburentes que calentando calderas especiales permiten convertir la energía en vapor o electricidad, y cuyas escorias, inertes, pueden servir de material de relleno o para fabricar productos cerámicos.

Todos estos sistemas, pueden o no ir acompañados de una selección previa (triaje) de los productos recuperables o perjudiciales : piedras, materiales metálicos, hoja de lata, trapos, papel, huesos y vidrios principalmente. Los cuales debidamente desinfectados en instalaciones ad-hoc son reincorporados a la industria local.

La principal dificultad del Servicio de Limpieza pública es que es caro, y que hay que contar con cifras de 50 a 75 pesetas por habitante y año, para organizarlo y mantenerlo adecuadamente. 


\section{Tráfico y transportes.}

Entre los servicios del vuelo, diremos breves palabras sobre el de tráfico y transportes, ya que aunque no lo parece, tiene un carácter sanitario, no solamente por la influencia de los contagios que pueden producirse en los vehículos de servicio público, sino porque si se considera el número de accidentes y muertes que hoy día se producen en las modernas ciudades, cabe hablar de "una enfermedad del tráficon que los higienistas han de combatir.

Muy esquemáticamente he de hablar del tráfico en el urbanismo, y ello para fijarme en las normas de implantación y reformas urbanas más que en las de explotación.

E1 señalamiento de los pasos de peatones en forma clara y visible. El establecimiento de la circulación única en aquellas calles que tengan agotada su capacidad de circulación en ambos sentidos (sin abusar de la medida por lo que encarece el recorrido inútil de los vehículos). La implantación de señales bien estudiadas de alternancia de tráfico.

La disposición de adecuados lugares de estacionamiento que descongestionen las calles principales. El adecuado emplazamiento de guardias con instrucciones sencillas y claras, adecuadas a su mentalidad. $\mathrm{Y}$ el rígido cumplimiento del Código de Circulación en vigor, con las medidas urbanas mínimas a emplear.

Pero hay que ir pensando ya, en los lugares congestionados de nuestras urbes, en obras de cruce a distinto nivel de los principales torrentes circulatorios, cuyo magnífico resultado está a la vista en las ciudades europeas y americanas. Incluso en la ejecución de calles especiales: elevadas, enterradas o mixtas, para el tráfico de tránsito. Y sobre todo en una ordenación de los medios de transporte colectivos: tranvías, autobuses, trolebuses y Metropolitano.

Cada uno tiene sus ventajas e inconvenientes y es en un acoplamiento de ellos, sin poner el veto a ninguno más que en algún sector especial, en el que reside el secreto de una política urbanista moderna. 


\section{Piscinas.}

El otro servicio del vuelo es el de piscinas.

La higiene colectiva exige hoy día en las ciudades el establecimiento de piscinas en las que pueda practicarse tan importante necesidad y tan favorable deporte, en todo tiempo. Ello requiere que, salvo en nuestras regiones cálidas, en que las abiertas (o al aire libre) pueden ser utilizadas todo el año, ha de tenderse a las cerradas y con acondicionamiento de aire y agua. De lo contrario, por mucho que en la Prensa se hable de las ventajas de la natación, y por muchas campañas que promuevan las Sociedades deportivas, todo será ficticio.

En las piscinas hay que prestar más atención al contenido que al continente, que no es lo que ahora suele suceder.

Deben de constar de cabinas en número adecuado à los usuarios que se prevean, en proporción de $\frac{\mathrm{c}}{3} \mathrm{a} \frac{\mathrm{c}}{5}$, siendo c la capacidad del vaso en $\mathrm{m}^{3}$.

Instalación de duchas con baños de pies, a través del cual sea forzoso pasar antes de llegar al vaso de natación, para prever las posibilidades de contaminación.

Inaccesibilidad del público al estanque y, sobre todo, mantenimiento de las adecuadas condiciones bacteriológicas del agua en todo momento.

De lo contrario, las otitis, meningitis, como infecciones del oído; conjuntivitis y tracoma de los ojos; resfriados, sinusitis y renitis de la nariz; tonsilitos y faringitis de la garganta ; forunculosis, granos, sarna, sarpullidos, pediculosis y eczemas, de la piel; blenorragia y sífiiis, e incluso infecciones gastrointestinales, estarán a la orden.

Esto puede conseguirse con renovación natural del agua, pero aparte de su excesivo coste de líquido, no garantiza plenamente la. asepsia.

Es casi imprescindible establecer el circuito cerrado: salida de agua por rejilla, coagulación y filtración de la misma, airea- 
ción, cloración posterior y calentamiento para mantener la temperatura requerida.

Las condiciones a alcanzar para el agua de las piscinas con estas instalaciones son resumidas:

Temperatura, 22 a 24 grados.

Limpidez, de un grado de la escala de turbidez americana, con la que puede verse perfectamente a cuatro metros de profundidad.

Sin olor ni sabor extraños.

Color natural, pues el verdoso indica presencia de algas, bacterias por centímetro cúbico medias en agar a $37^{\circ}$ a las veinticua. tro horas por debajo de 100 y con máximo accidental de 200 .

Sin B. Coli en $10 \mathrm{~cm}^{3}$.

Cloro libre en cualquier lugar de 0,25 a 0,50 p. p. m. Alcalinidad entre 7,5 y 7,8 de PH. (mínimo accidental, 7,2).

La coagulación con sulfato de alúmina requiere unos cinco gramos por metro cúbico o del doble en las horas de máxima afluencia de bañistas.

Los filtros más comúnmente empleados son los rápidos a presión, con superficie aproximada a un metro cuadrado por cada 200 litros tratados, por minuto.

En grandes piscinas puede reducirse hasta un metro cuadrado por 350 litros por minuto.

La aireación suele hacerse para eliminar olores y gases nocivos y para que, disolviendo oxígeno, resulte el agua con los caracteres de fresca.

La cloración o cloraminación suele hacerse con cloro gaseoso, con dosis medias de 0,6 (p. pm.)

Puede emplearse también el ozono, los rayos ultravioleta o la depuración oligodinámica por metales (cobre, mercurio y, sobre todo, plata).

La duración media del ciclo puede ser (llamando $c$ a la capacidad del vaso) :

Piscinas cubiertas: De 3,5 a 4 horas y 4,8 a $4,1 c$ litros.
Abiertas normales :
5
$3,3 \mathrm{c}$.
id. grandes :
6
$2,8 \cdot c$. 
El caudal por segundo, de la circulación, debe oscilar para piscinas normales entre 25 y 75 litros.

La longitud de los vasos debe șer una parte alícuota de 100 (100, $50,33,3,25$ o 20).

En piscinas de adultos, da parte menos profunda debe tener de uno a 1,20 metros, a 1,40 a 1,60 en el centro, aumentando después hasta tres a 3,50 en los últimos tres metros, para permitir saltos desde trampolines de 4,5 y cinco metros.

$\mathrm{Su}$ revestido debe ser de azulejos blancos o enlucido de cemento blanco, bien hecho y lavable.

De haber solarium en la piscina debe éste tener superficie en sombra y penumbra para descanso de la exposición al sol.

La ventilación debe estudiarse cuidadosamente para asegurar la extracción de las condensaciones (que son variables en cada dependencia), y evitar los intercambios de aire entre piscina, cabinas, vestíbulos y sala de duchas, cuyas temperaturas respectivas deben ser 25 a $27^{\circ} ; 18$ a 22 , intermedia entre cabinas y exterior, y 28 a $30^{\circ}$.

Con estas normas se lograrán piscinas eficaces, aunque sean menos bonitas que algunas de las que disfrutamos.

\section{Alumbrado.}

$Y$ finalmente, el servicio de alumbrado merece la pena de ser cuidado cada vez más por la influencia que tiene en la vida moderna, en el confort, en la seguridad y la amenidad de las calles.

Nos limitaremos a indicar lo siguiente:

A los efectos de flúido luminosos a alcanzar, deben dividirse las vías públicas en :

Vías blancas o comerciales.

Vías de principal circulación.

Vías de reparto de tráfico.

Vías residenciales.

Los tipos de armaduras (reflectores o bordillos) a emplear han de estudiarse con arreglo a las unidades de iluminación que se 
quieran alcanzar en las calzadas, y deben evitar la dispersión del flujo en el ambiente.

De ahí se deduce la separación, altura e intensidad de las mismas, habida cuenta del efecto de deslumbramiento que pueden producir.

Modernamente las redes alimentadoras se establecen a base de puestos de transformación subterráneos, emplazados estratégicamente para atender sectores definidos con pocas pérdidas de carga.

\section{Ideas generales sobre Bilbao.}

Terminada ya esta exposición de carácter general, parece obligado hacer alguna alusión al caso concreto de Bilbao, que conozco hace años por haber tenido bastantes contactos profesionales, por mis visitas frecuentes a la ciudad, y por el cariño con que he seguido sus esfuerzos por hacerse una gran urbe.

De todos modos he de pedir perdón si alguno de los datos o información que me ha servido de base no resultara exacto, e influyera por tanto en mi opinión.

Veamos cómo está el problema del abastecimiento de aguas.

En el luminoso informe emitido en 1925 por los eminentes ingenieros de Caminos don Severino Bello, don José Orbegozo g don Pedro González Quijano, en unión del abogado don Juan Migoya sobre el problema del abastecimiento de aguas a la capital, se hacía el análisis del crecimiento de la población y el cálculo de la que habría de contarse en un período de 50 años, que es la previsión lógica: técnica y económicamente hoy día úniversalmente admitida.

Se llegó así a deducir que en 1975 la población abastecida sería la siguiente :

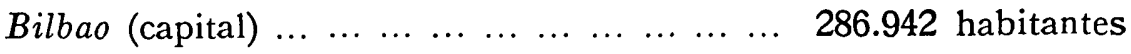

Futuras anexiones: Baracaldo, Erandio, Gue-

cho, Lamiaco, Portugalete, Santurce y

Sestao

$$
\text { Total ... ... ... .. } 450.589 \quad \text { " }
$$

con un índice medio de crecimiento de 1,0229. 
Hoy día, justo a medio camino, la población de Bilbao, según el censo de 1948, es de 230.507. Carezco de datos para juzgar la de los núcleos de futura anexión, pero admitiendo la misma proporcionalidad (lo cual se ajustará mucho a la realidad), se llega a una cifra de cerca de 400.000 habitantes.

Es decir, que el cálculo hecho para 1975 será sobrepasado ampliamente, si el fenómeno de concentración de personas en las grandes aglomeraciones continuara, como (por suerte o por desgracia Iquién lo sabe!) se viene acentuando en los últimos años.

En cuanto a la dotación necesaria ya se fijó entonces la de 250 litros por habitante y día ; superior a los 200 que señalaba el Estatuto Municipal ya entonces vigente.

La realidad de la vida moderna es que cuando el vecindario adquiere hábitos higiénicos y de confort, y cuando los servicios urbanos están bien atendidos, este consumo crece por encima de los 300 litros por habitante y día.

Las poblaciones progresivas ya alcanzan esta cifra y aún la sobrepasan. Y para no citar el caso de Madrid para que no se nos alegue que es especial por estar atendido su abastecimiento por un organismo estatal: el Canal de Isabel II, indicaremos el de Pamplona, que hace unos años solicitó de la Comisión Central de Sanidad Local, y yo tuve el gusto de informarlo favorablemente como Jefe de la Sección de Ingeniería Sanitaria en el Ministerio de la Gobernación, el aumento oficial de la dotación a 300 litros por habitante y día.

En virtud de los razonamientos acertadísimos del informe se compararon los proyectos presentados, que fueron los siguientes:

Lekusaso (Vizcaya), para 100 litros por segundo derivados del río Lekusaso, con embalse de 1.000 .000 de metros cúbicos.

Oiz (Vizcaya y Alava), para 700 litros por segundo, de manantiales del monte Oiz.

Abadiano, para 1.000 litros por segundo (ampliables a 2.000), derivados de los ríos Mañaria y Achante, con embalse lateral de 16,5 millones de metros cúbicos.

Indusi, para 700 litros por segundo en una solución y 1.500 en otra, derivados de los ríos Indusi y Urquiola, con embalse en 
el primero de 7 millones en una solución y 15 en la otra, y aprovechamientos hidroeléctricos de 1.080 y $2.300 \mathrm{HP}$ respectivamente.

Orozco, para 600 litros por segundo, derivados de los ríos Achuri, Olarrieta y Zubieta, con un embalse en cada uno, de capacidad total de 6,7 millones de metros cúbicos y aprovechamiento de $350 \mathrm{HP}$.

Bayas, para 2.000 litros por segundo, derivados de los ríos Bayas y Marquine (vertiente del Ebro), con embalse de 16,5 millones de metros cúbicos y energía utilizable de $9.800 \mathrm{HP}$.

Asón (Santander y Vizcaya), para 1.320 litros por segundo de manantiales y con $350 \mathrm{HP}$ de energía útil. Y

Ordunte (Burgos), para 1.500 litros por segundo, derivados de los ríos Ordunte y Cerneje (vertiente del Ebro), con embalse en el primero de 21 millones de metros cúbicos y con aprovechamiento de $1.432 \mathrm{HP}$.

Y se eligió el del Ordunte, gracias al cual Bilbao ha podido beber y crecer hasta el día.

Pero las previsiones han sido desbordadas y es forzoso ya pensar en el abastecimiento colectivo integral, cuya solución más lógica en el momento actual en que se ha producido el hecho de los saltos del Zadorra, es la de aprovechar las aguas de los miṣmos, que reunen adecuadas condiciones de potabilidad (previa corrección bacteriológica) y estudiar su conducción a Bilbao y su ría, y su distribución mediante la construcción de depósitos de regulación convenientemente emplazados en relación con los núcleos actuales y sus expansiones previstas en el plan de ordenación del Gran Bilbao, y las adecuadas redes distribuidoras, concebidas y desarrolladas con vistas no a las necesidades presentes, sino a las de un futuro inmediato.

Saneamiento.

Bilbao ya tiene un plan de ordenación redactado con todas las garantías de acierto y aprobado.

¿Qué lejos está de este ambicioso plan y bellos planos aquel Bilbao que en la colina de Miraville, en la orilla izquierda del 
Nervión aunaba en su pequeño recinto las inquietudes marineras con las ferrerías y la modestísima industria naval!

$\mathrm{Y}$ qué lejos las normas del fuero de Logroño que don Diego López de Haro le otorgó al fundar el villazgo con las contenidas en las Ordenanzas del Gran Bilbao.

Ya no hay, pues, razón para no acometèr con toda urgencia el plan general de saneamiento de las futuras urbanizaciones para ir acometiendo, de abajo arriba, los grandes colectores de las numerosas cuencas que la atormentada topografía del terreno contiene.

Ignoro si se está estudiando ya o no; pero si así no es, creo que urge hacerlo, pues el dinero que se invierta en este gran proyecto de conjunto, se verá recuperado varias veces con sólo evitar maniobras mal hechas, obras insuficientes, o freno en las urbanizaciones periféricas.

Pero el gran problema sanitario de Bilbao es el acabar con ei estado actual de colector natural de toda clase de aguas residuales que disfruta hoy la ría básica, cuyas aguas parecen decir con su aspecto externo: bien está que seamos industriales y no tengamos la transparencia y las virtudes de las rías infecundas; pero ipor Dios! descargadnos de los residuos antihigiénicos que nos envenenan.

El problema hoy día no es difícil, pues existen procedimientos modernos que facilitan la rápida depuración a completar en el agua. Claro que se precisa un detenidísimo estudio de las cuencas vertientes, de los colectores generales a prever, de los emplazamientos de las instalaciones de tratamiento y de la influencia de la autodepuración en los efluentes a verter.

$\mathrm{Y}$ aunque las cuestiones y obras sanitarias nunca son baratas, sí creo poder afirmar que de este meditado estudio pueden salir fórmulas que encajen en las disponibilidades municipales; sobre todo teniendo en cuenta que la ejecución de obras puede escalonarse en varios años.

\section{Canalizaciones.}

Creo que será, de ahora en adelante, cuando empezará Bilbao a sentir la importancia del problema; y creo también que no está 
lejano el día que comience a construir sus galerías de servicio, a menos que la evolución del aprovechamiento de la energía atómica vaya simplificando cables y tubos en las urbes.

\section{Pavimentaciones.}

En conjunto el Servicio de Vías Públicas bilbaíno está perfectamente orientado. Convendrá no obstante hacer entrar en juego razones técnicas para las futuras pavimentaciones, y acelerar de acuerdo con el 'Estado la ejecución de las grandes arterias de penetración y circulación incluída en el Plan aprobado, con las modificaciones de detalle que el estudio más acoplado al terreno "de prueba” de este valle del Nervión y de sus afluentes, especialmente el de Asúa, aconseje.

\section{Limpieza pública.}

Si las graves circunstancias que hemos sufrido dan paso a una normalidad, y puede contarse con la adquisición de elementos especializados mecánicos de barrido y riego, convendrá ir implantándolos con amplitud.

Asimismo parece va llegando la hora de exigir un modelo único de cubo de recogida de basuras caseras y adoptar camiones de cierre hermético adecuados a ese cubo, estableciendo una recogida y transporte en las primeras horas de la mañana con sus itinerarios perfectamente organizados.

$Y$ si los resultados de la trituración no son satisfactorios, completarlos con una incineración que permita desembarazarse higiénicamente de las basuras no absorbidas por el campo circundante.

Tráfico y transportes.

La construcción por Obras Públicas de las vías de penetración, completada por la ejecución de las de circulación previstas en el plan de ordenación del Gran Gilbao debe ayudar a resolver el problema del tráfico y de los transportes, si bien en este aspecto hay que reconocer que Bilbao está a la cabeza de nuestras ciudades. 
Si se construye el túnel de enlace con el valle de Asúa y si se disponen cruces a distinto nivel en puntos estratégicos, la circulación urbana se perfeccionará y Bilbao podrá hacer frente a la "prisa), dueña y señora de las modernas ciudades y en general del mundo actuals

Piscinas y alumbrado.

Póco puedo decir de las piscinas, pues las especiales circunstancias de clima y costumbres bilbaínas, y quizá la proximidad del mar, dan un matiz "sui géneris" a este servicio.

$\mathrm{Y}$ en cuanto a alumbrado, creo que basta seguir el camino iniciado para no perder la condición de ciudad blanca que hoy tiene esta capital.

José Paz Maroto

Ingenitro Jefe de Ingeniería Sanitaria de la Dirección General de Sanidad 